\title{
Improving ductility by increasing fraction of interfacial zone in low C steel/ 304 SS laminates
}

\author{
Jinyan $\mathrm{He}^{\mathrm{a}, \mathrm{b}}$, Yan $\mathrm{Ma}^{\mathrm{a}, \mathrm{b}}$, Dingshun Yan ${ }^{\mathrm{a}}$, Sihai Jiao ${ }^{\mathrm{c}}$, Fuping Yuan ${ }^{\mathrm{a}, \mathrm{b}, *}$, Xiaolei $\mathrm{Wu}^{\mathrm{a}, \mathrm{b}}$

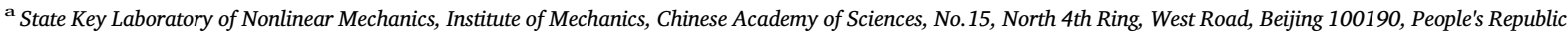 \\ of China \\ ${ }^{\mathrm{b}}$ School of Engineering Science, University of Chinese Academy of Sciences, Beijing 100049, People's Republic of China \\ ${ }^{\mathrm{c}}$ Baosteel Research Institute, Baoshan Iron \& Steel Co., Ltd., Shanghai 201900, People's Republic of China
}

\section{A R T I C L E I N F O}

\section{Keywords:}

Laminates

Hot-rolled bonding

Strain gradient

Back stress hardening

Geometrically necessary dislocations

Mechanical properties

\begin{abstract}
A B S T R A C T
Interfaces have been found to play an important role in mechanical behaviors of metals and alloys with heterogeneous microstructures. In present study, low C steel/304 stainless steel (SS) laminates with varying fractions of interfacial zone were fabricated by hot-rolled bonding, annealing and pickling, then cold rolling, subsequent annealing followed immediately by water quenching to study the effect of fraction of interfacial zone on the tensile properties. Heterogeneous distributions in chemical composition, grain size, phase and hardness were observed in the interfacial zone. The yield strength was observed to be constant with varying fractions of interfacial zone, while the ultimate strength and the uniform elongation were found to increase with increasing fraction of interfacial zone. High density of geometrically necessary dislocations (GNDs) were found to distribute in the interfacial zone and show a peak at the interface due to the mechanical incompatibility across the interface. Moreover, the density of GNDs was found to increase with increasing tensile strain in the interfacial zone. Back stress hardening was found to play an important role in the laminates, especially at the elasto-plastic transition stage. Higher fraction of interfacial zone can induce stronger back stress hardening and higher density of GNDs in the samples, thus resulting in better tensile ductility.
\end{abstract}

\section{Introduction}

Superior combination of strength and ductility is always desirable in many structural applications. However, these two properties are generally considered mutually exclusive: an increase in strength is inevitably accompanied with sacrifice of ductility $[1,2]$. Therefore, it has always been a challenge to impart greater ductility to these high strength metals and alloys through novel microstructure designs [3-6]. Recently, heterogeneous structures have been proposed in metals and alloys to achieve both high strength and ductility $[7,8]$. For example, several strategies employing heterogeneous structures have been reported to produce superior tensile properties, including nanotwinned grains $[6,9,10]$, nanodomained structure $[11,12]$, grains with nanoprecipitates [13,14], laminate structure [15-24], bimodal structure [25], heterogeneous lamella structure [26,27], and gradient structure [28-32]. Among them, laminate structure has attracted extensive interests recently for their potential in achieving excellent tensile properties by tailoring microstructural parameters, such as interface spacing and hardness difference between layers [15-24].

In these heterogeneous structures, high density of interfaces with different mechanical properties across them have been found to play important roles for strain hardening [7,8,15-19,21-24]. For example, high density of dislocations have been observed to accumulate around the interfaces between nanodomained grains/nano-precipitates and large grain matrix for strengthening and strong strain hardening, enabling simultaneous high strength and large uniform elongation in the nanodomained structure and the structure with nano-precipitates [11-14]. Twin boundaries (TBs) can act as barriers for dislocation motion to contribute to strengthening on one hand, and TBs can also provide adequate pathways for dislocation glide and trapping sites for pile-up of dislocations to accommodate significant plastic deformation on the other hand $[6,9,10]$. In gradient structures $[28,29]$, interfaces between different layers at various depths have been believed to significantly contribute to the observed extra strengthening and extra strain hardening. Interfaces between ultrafine grained (UFG) lamella and coarse grained (CG) lamella have been found to be responsible for

\footnotetext{
* Corresponding author at: State Key Laboratory of Nonlinear Mechanics, Institute of Mechanics, Chinese Academy of Sciences, No.15, North 4th Ring, West Road, Beijing 100190, People's Republic of China.

E-mail addresses: hejinyan@imech.ac.cn (J.He), mayan@imech.ac.cn (Y. Ma), dyan@imech.ac.cn (D. Yan), shjiao@baosteel.com (S. Jiao), fpyuan@lnm.imech.ac.cn (F. Yuan), xlwu@imech.ac.cn (X. Wu).
} 
the combination of UFG strength with CG ductility in heterogeneous lamella structure $[26,27]$. The superior tensile properties observed in heterogeneous lamella structure and gradient structure have also been attributed to the back-stress hardening and strengthening, which are caused by the strain gradient evolution and the pile-up of geometrically necessary dislocations (GNDs) at interfaces with different mechanical properties [26-29].

The distribution of GNDs across interfaces should be highly related to the strain gradients across interfaces, which are determined by the magnitude of the mechanical incompatibility at both sides of interfaces $[15,16,26,29,33,34]$. While, the details of GND density distribution across interfaces and their dependence on interface spacing in laminate structure are not well documented and require further investigations $[15,16]$. Moreover, how the GND density distribution and microstructural characteristics across interfaces evolve with plastic deformation are still in vague. In this regard, low C steel/304 stainless steel (SS) laminates by hot-rolled (HR) bonding (commercially produced in Baosteel, China) were used in this work as a studying case. Low C steel/304 SS laminates not only can achieve superior mechanical properties by tailoring the microstructures, but also can provide strong corrosion resistance and reduce the life-cycle costs by using the combined properties of both the corrosion resistance of 304 SS surface layers and the high strength of low $\mathrm{C}$ steel base layer. The evolution of GNDs along with tensile deformation, the interface spacing effects on the tensile properties and the corresponding deformation mechanisms were then systematically studied in low C steel/304 SS laminates.

\section{Materials and experimental methods}

Chemical compositions of commercial low C steel and 304 SS are $0.2 \mathrm{C}-1.0 \mathrm{Mn}-0.02 \mathrm{Ti}-0.04 \mathrm{Nb}$ and $0.05 \mathrm{C}-1.2 \mathrm{Mn}-19 \mathrm{Cr}-10 \mathrm{Ni}$ (all in mass \% and with the balance of $\mathrm{Fe}$ ), respectively. HR bonding was used to bind one low C steel plate and two 304 SS plates. In this study, the three $400 \mathrm{~mm} \times 400 \mathrm{~mm}$ samples were taken from the commercial products with 1:8:1 thickness ratio of 304 SS to low carbon steel to 304 SS, and total thickness is about $10 \mathrm{~mm}$. Then the laminates were fabricated by HR bonding between $1423 \mathrm{~K}$ and $1173 \mathrm{~K}$, and the HR slabs have a final thickness of about $3.3 \mathrm{~mm}$. The HR process was exactly symmetric, and the slabs were flat after HR process. In order to achieve good bonding interfaces with high bonding strength, the HR slabs were annealed at $1270 \mathrm{~K}$ followed by fast cooling with $30 \mathrm{~K} / \mathrm{s}$ cooling rate and pickling. Next, the slabs were then cold-rolled (CR) under room temperature into plates with thicknesses of $3.3,2.5,1.5 \mathrm{~mm}$, and their thickness reductions are $0 \%, 24 \%, 55 \%$, respectively. The fractions of thickness reduction for individual layers in laminates were nearly the same during $\mathrm{CR}$, i.e., the 1:8:1 thickness ratio was maintained after $\mathrm{CR}$. The $\mathrm{CR}$ process was also exactly symmetric and the CR plates were flat. The work roll has a radius of $85 \mathrm{~mm}$, the rolling speed is $1 \mathrm{~m} / \mathrm{s}$, and the thickness reduction for every rolling is $0.1 \mathrm{~mm}$. After CR, the materials were then annealed at $1193 \mathrm{~K}$ for $15 \mathrm{~min}$, followed immediately by water quenching (WQ). In summary, the samples are identified as CR0\% + WQ sample, CR24\% + WQ sample and CR55\% + WQ sample.

The plate specimens for mechanical testing have a dog-bone shape, and the dimensions of gauge section are $15 \times 5.5 \times 3.3 \mathrm{~mm}^{3}$, $15 \times 4.2 \times 2.5 \mathrm{~mm}^{3}, 10 \times 2.5 \times 1.5 \mathrm{~mm}^{3}$. The quasi-static uniaxial tensile tests and load-unload-reload (LUR) tests were conducted using an Instron 5565 testing machine at room temperature and at a strain rate of $5 \times 10^{-4} / \mathrm{s}$ under displacement control. Three tests were conducted for each specimen to check the repeatability. The tensile direction was parallel to the rolling direction. During LUR tests, the specimens were first stretched to a designated strain at strain rate of $5 \times 10^{-4} / \mathrm{s}$, then the specimens were unloaded by the stress-control mode to $20 \mathrm{~N}$ at the unloading rate of $200 \mathrm{~N} / \mathrm{min}$, followed by reloading at strain rate of $5 \times 10^{-4} / \mathrm{s}$. An extensometer was used to accurately measure and control the strain during the tensile tests and LUR tests. The distributions of micro-hardness across interfaces for various samples before and after tensile tests were also obtained on the polished sample surfaces using a Vickers diamond indenter under a load of $5 \mathrm{~g}$ for $15 \mathrm{~s}$ dwell time. Ten groups of measurements for each point were obtained, the average value was taken and the error bar was also provided.

Before and after tensile tests, optical microscope (OM), electron back-scattered diffraction (EBSD) and transmission electron microscopy (TEM) were used to characterize the microstructures. Scanning electron microscopy (SEM) was also used to characterized the fracture surface. The surfaces for OM and EBSD were first grinded to 3000 grit with sandpapers, and then polished by a $0.05 \mu \mathrm{m} \mathrm{SiO}_{2}$ aqueous suspension, followed by electro-polishing in a solution of $5 \% \mathrm{HClO}_{4}$ and $95 \%$ alcohol at $-20^{\circ} \mathrm{C}$ and $37 \mathrm{~V}$. Thin disks with thickness of about $200 \mu \mathrm{m}$ were machined first, and then mechanically polished down to about $40 \mu \mathrm{m}$, followed by a twin-jet polishing using a solution of $5 \%$ perchloric acid and $95 \%$ ethanol at $-20^{\circ} \mathrm{C}$ and $25 \mathrm{~V}$ for TEM observations. A scanning step of $100 \mathrm{~nm}$ was used for EBSD acquisition. Grain boundaries (GBs) were defined by misorientation larger than 15 degrees. Kernel average misorientation (KAM) was calculated against the first nearest neighbor ignoring the misorientation larger than 3 degrees [16].

\section{Results and discussions}

\subsection{Microstructures}

The microstructures of the area near the interfaces for various samples are shown in Fig. 1. Fig. 1a1-c1 show the images for the inverse pole figure (IPF) of various samples, while the images for the phase distribution of various samples are displayed in Fig. 1a2-c2. The straight interfaces can be easily identified from these figures, and the microstructures across the interfaces are highly heterogeneous. Lath martensite are formed during WR on the side of low $\mathrm{C}$ steel. The side of 304 SS shows a phase of austenite and gradient grain size distribution near the interface after WQ. The distributions of gradient grain size near the interface for the side of 304 SS are similar for all CR + WQ samples with varying thickness reductions of CR. As shown later, the differences in the hardness distributions for various $\mathrm{CR}+\mathrm{WQ}$ samples are trivial and can be ignored.

Representative TEM images at both sides close to the interfaces are provided for the CR0\% + WQ sample in Fig. 2. Fig. 2a shows a schematic illustrating where the TEM images were taken. Fig. $2 \mathrm{~b}$ shows the TEM image for the side of 304 SS at the interface, while Fig. 2c displays the TEM image for the side of low $\mathrm{C}$ steel with a distance of about $100 \mu \mathrm{m}$ to the interface. Lath martensite can be clearly observed for the side of low $\mathrm{C}$ steel, while both equi-axed grains and elongated grains can be observed for the side of 304 SS. Based on numerical TEM images, the statistical distributions for the grain size of 304 SS austenite and the width of lath martensite are shown in Fig. 2d. As observed, the 304 SS austenite has an average grain size of about $323 \mathrm{~nm}$, while the lath martensite has an average feature size of about $249 \mathrm{~nm}$.

Fig. 3 shows the micro-hardness distributions across the interfaces for various samples. As indicated, the micro-hardness shows a plateau away from the interfaces at both sides for various samples. The plateau value of hardness for the side of low C steel (about $475 \mathrm{Hv}$ ) is much higher than that for the side of 304 SS (about $225 \mathrm{Hv}$ ) due to the martensite transformation for the low C steel during WQ. Due to the heterogeneous microstructures across the interfaces, the hardness is highly inhomogeneous across the interfaces for various samples. An interfacial zone (IZ) is defined for various samples (as marked by shaded areas in Fig. 3), in which the hardness exhibits a gradient distribution at both sides of the interface. At the side of 304 SS in the IZ, the hardness is observed to gradually increase from the edge of IZ towards the interface, which is due to the gradient distribution of grain size (larger grain size at the edge of IZ, smaller grain size at the interface). While, the hardness is observed to decrease from the edge of IZ 


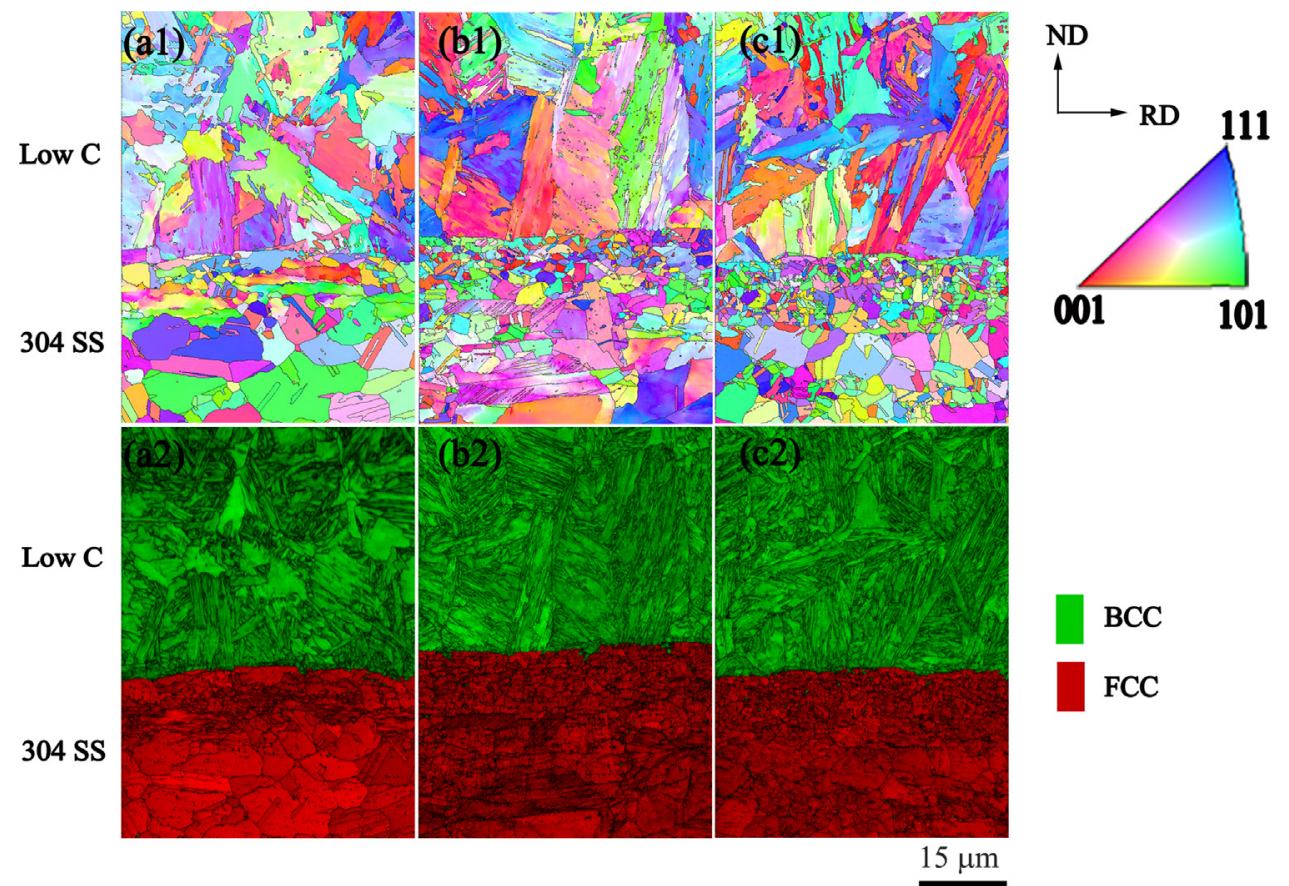

Fig. 1. IPF images across the interface for various samples: (a1) CR0\% + WQ sample; (b1) CR24\% + WQ sample; (c1) CR55\% + WQ sample. Phase distribution images across the interface for various samples: (a2) CR0\%+WQ sample; (b2) CR24\%+ WQ sample; (c2) CR55\% + WQ sample.

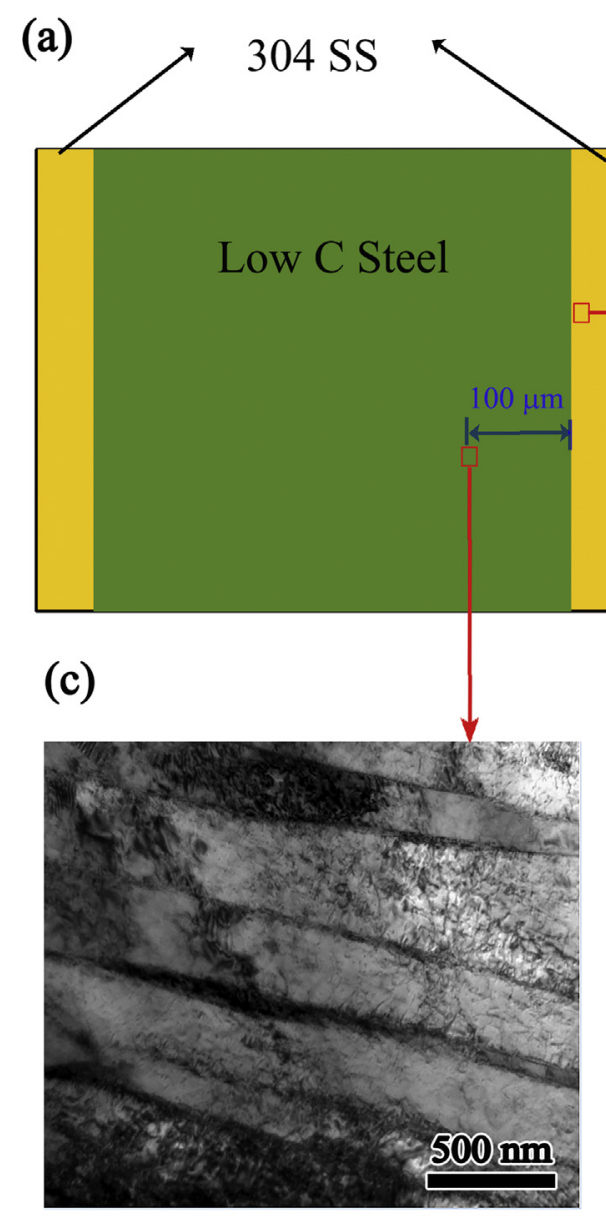

(b)

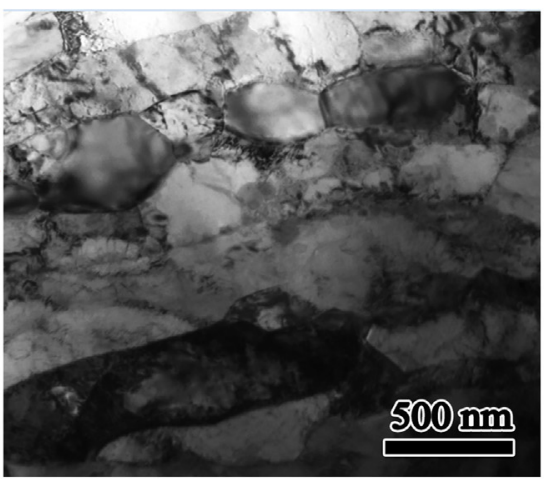

(d)

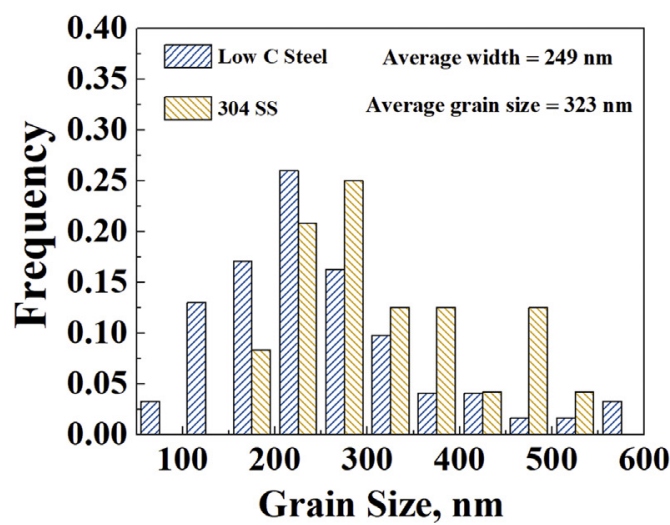

Fig. 2. (a) TEM image at the interface in the CR0\% + WQ sample for the side of 304 SS; (c) TEM image with a distance of about $100 \mu \mathrm{m}$ to the interface in the CR0\% + WQ sample for the side of low C steel. The corresponding grain size distributions for the side of: (b) 304 SS; (d) low C steel. 

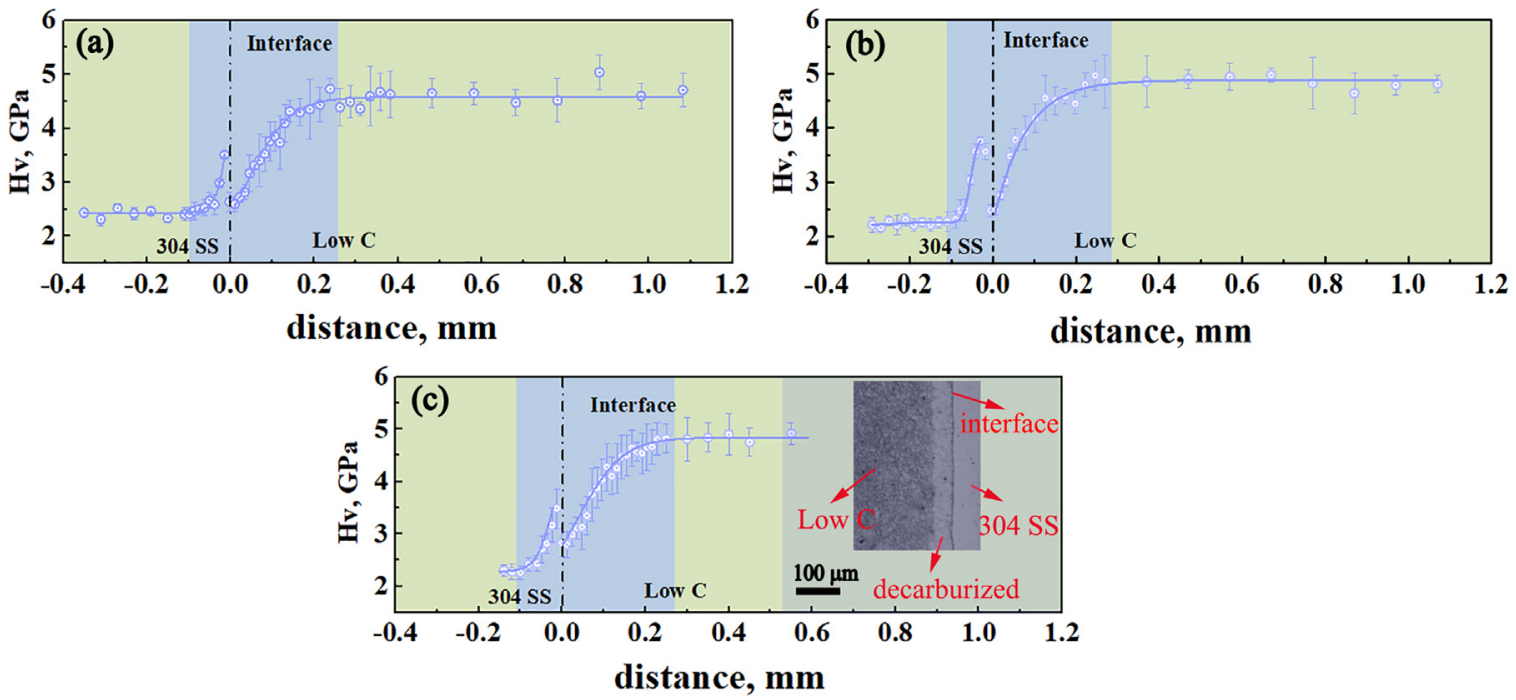

Fig. 3. Vickers micro-hardness distributions across the interface for various samples: (a) CR0\%+WQ sample; (b) CR24\%+WQ sample; (c) CR55\%+WQ sample.

towards the interface at the side of low C steel, which could be due to the formation of a decarburized layer near the interface for the side low $\mathrm{C}$ steel during HR bonding (as shown by the OM image in the inset of Fig. 3c). The carbon contents both near the interface and far from the interface have also measured by combustion test method for both sides (The samples for combustion test method have a mass of $1 \mathrm{~g}$, and the accuracy of measurement is $0.3 \mathrm{ppm}$ for carbon content). The results also confirmed the existence for the decarburized layer (The carbon contents are $0.217 \%$ and $0.055 \%$ near the interface and far from the interface, respectively, for the side of 304 SS; The carbon contents are $0.128 \%$ and $0.198 \%$ near the interface and far from the interface, respectively, for the side of low $\mathrm{C}$ steel). This decarburized layer could be formed by carbon diffusion to the side of 304 SS during high temperature rolling. As we know, the fraction of martensite transformation may be decreased when the carbon content is reduced in the decarburized layer. The carbon content should be less when the distance is closer to the interface. Thus, there should exist a gradient distribution of martensite phase in the IZ (higher fraction of martensite phase at the edge of IZ, lower fraction of martensite phase at the interface), resulting in a gradient hardness distribution at the side of low C steel in the IZ (as indicated in Fig. 3). As observed from the 304 SS side to the low C steel side, it is interesting to note that there exists a sharp change and a discontinuity in hardness at the interface.

It has been a challenge to investigate the interface spacing effect or the effect of fraction of IZ on the mechanical properties of laminates since it is not easy to fabricate samples with varying interface spacing and also with similar microstructure and similar hardness distribution across the interface $[15,16,24]$. It is interesting to note that the distribution of hardness across the interfaces and the hardness away from the interfaces are observed to be very similar for various samples. Moreover, the width of IZ is also observed to be similar for various samples, while the fraction of IZ is found to increase with increasing thickness reduction of $\mathrm{CR}$ due to the different overall thicknesses for various samples. It should be reminded that two interfaces exist for each sample. Thus, the fraction of IZ is about $23 \%$ for the CR0\%+WQ sample, the fraction of IZ is about $28 \%$ for the CR2 $4 \%+$ WQ sample, and the fraction of IZ is about $46 \%$ for the CR55\%+WQ sample. Thus, it is a good opportunity to study the fraction of IZ only on the mechanical properties and the deformation mechanisms using the current $\mathrm{CR}+\mathrm{WQ}$ samples.

\subsection{Mechanical properties}

The tensile properties for various samples are displayed in Fig. 4.
Fig. 4a shows the engineering stress-strain curves, while Fig. 4b displays the curves for the true stress and the hardening rate $(\Theta)$ as a function of the true strain. The yield strength (YS), the ultimate strength (UTS) and the uniform elongation (UE) are plotted as a function of fraction of IZ in Fig. 4c and. Since three tests were conducted for each sample, the error bar is also provided in Fig. 4c and d. In Fig. 4a and b, the yielding points are marked by circles and the UTS points are marked by squares. As indicated, all samples show a round continuous yielding and strain hardening behaviors. Interestingly, the YS is almost the same for all samples (about $835 \mathrm{MPa}$ ), while the UTS and the UE increase with decreasing interface spacing or increasing fraction of IZ. The hardening rate (as shown in Fig. 4b) is also observed to increase with increasing fraction of IZ.

As indicated in Fig. 4, apparent strain hardening is observed during tensile deformation for all samples, which raises a critical issue: where is the strain hardening generated? In this regard, the Vickers microhardness $(\mathrm{Hv})$ distributions and the distributions of Vickers microhardness increment $(\Delta H v)$ across the interface after tensile deformation for various samples are measured and provided in Fig. 5a-c. As shown in Fig. 3, a hardness discontinuity is observed across the interface (from the side of 304 SS to the side of low C steel) before tensile loading for all samples. However, this discontinuity disappears after tensile deformation for all samples. This can be attributed to the deformation incompatibility and the strain partitioning across the interface, i.e., the hard domain for the side of 304 SS with small grains at the interface bears less strain and lower strain hardening while the soft domain for the side of low C steel (the decarburized layer) at the interface bears more strain and higher strain hardening during tensile loading. This deformation incompatibility will cause strong strain gradient across the interface. Then the average increments of Vickers micro-hardness after tensile deformation for the side of 304 SS, the side of low C steel and the whole sample are plotted as a function of fraction of IZ in Fig. 5d. It is observed that the average increments of Vickers micro-hardness for both sides increase with increasing fraction of IZ, indicating that a higher fraction of IZ can result in greater strain hardening at both sides. It is also interesting to note that the average increment of Vickers micro-hardness for the side of $304 \mathrm{SS}$ is larger than that for the side of low $\mathrm{C}$ steel in the CR0\%+WQ sample. However, the average increments of Vickers micro-hardness for the side of low $\mathrm{C}$ steel are observed to be much larger than those for the side of 304 SS in the CR24\%+WQ sample and the CR55\% + WQ sample. This means that higher fraction of IZ can make the hard martensite phase of low $\mathrm{C}$ steel to be more deformable under tensile loading, resulting in better tensile ductility. 
(a)

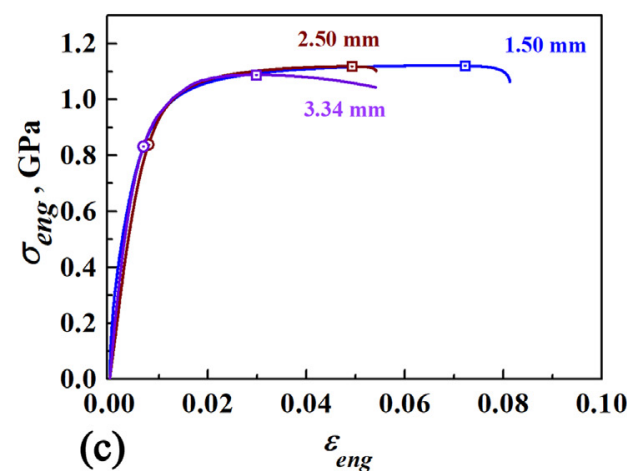

(b)

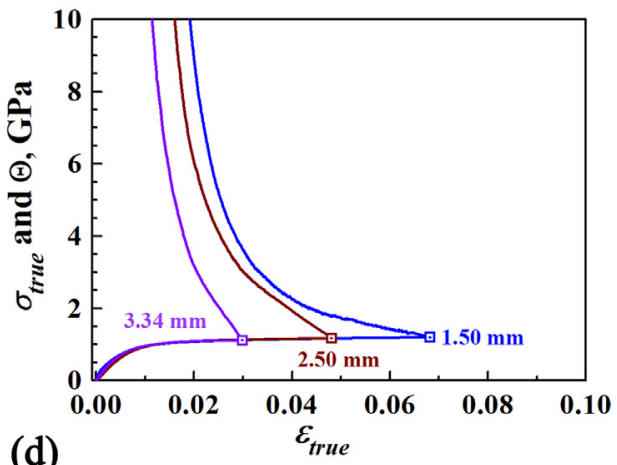

(d)

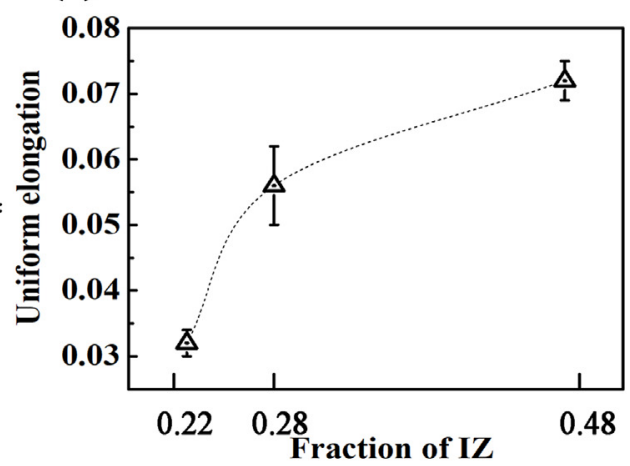

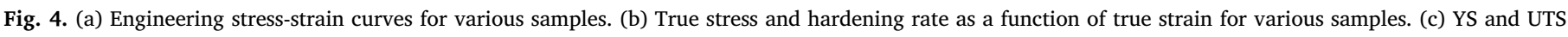
versus fraction of IZ. (d) UE versus fraction of IZ.

\subsection{EBSD mapping and GND characterization across interfaces}

In order to investigate the effect of fraction of IZ on the observed mechanical properties of the laminates, the EBSD images and the corresponding GND characterization of the area near the interface are provided. Fig. 6a1-d1 and Fig. 6a2-d2 show the IPF and phase distribution images at varying applied tensile strains $(0 \%, 2 \%, 5 \%$, UE) for the CR55\% + WQ sample. From the phase maps, it can be concluded that almost no phase transformation occurs during tensile loading for the 304 SS, which could be attributed to the relatively small UE (about $7.2 \%)$. It is well known that the sequence of deformation mechanisms in SS is dislocation behaviors first, and then deformation twins and phase transformation from small plastic strain to large plastic strain. The deformation twins and phase transformation generally occur after a critical plastic strain in SS [35]. Thus, with such a small UE, the plastic deformation at both sides is mainly carried by dislocation behaviors. (a)

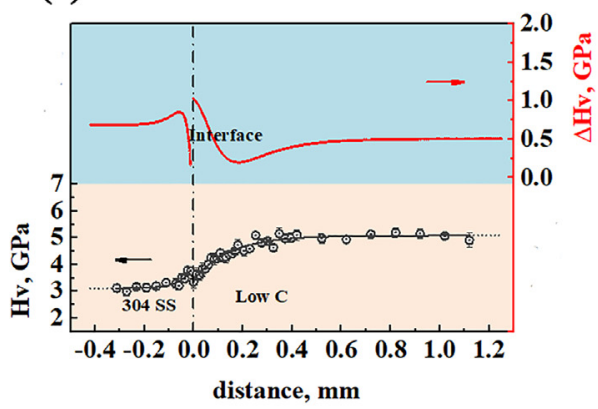

(c)

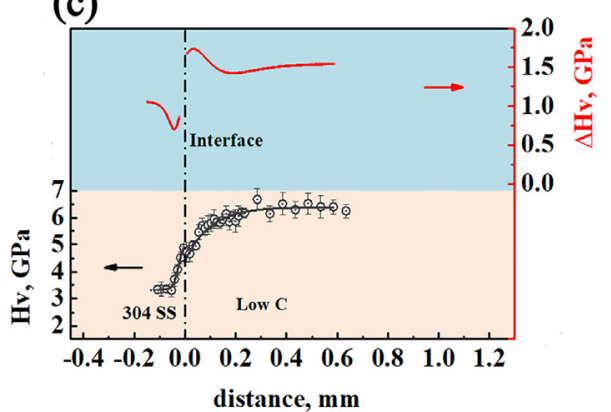

(b)

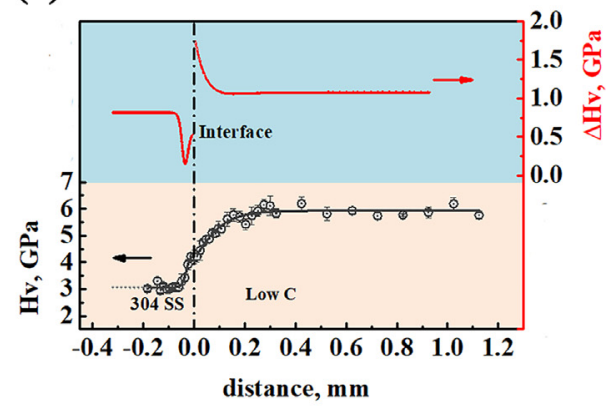

(d)

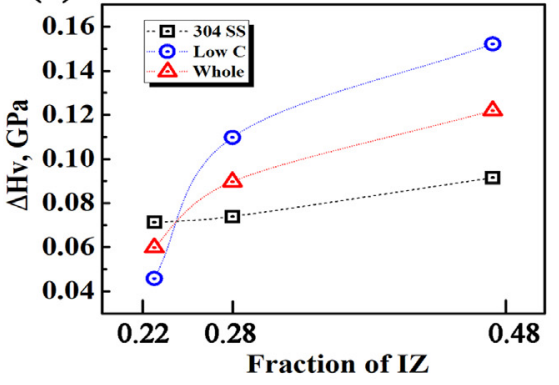

Fig. 5. Vickers micro-hardness distributions and distributions of Vickers micro-hardness increment across the interface after tensile deformation for various samples: (a) CR0\% +WQ sample; (b) CR24\% + WQ sample; (c) CR55\% + WQ sample. (d) Average increments of Vickers micro-hardness after tensile deformation versus fraction of IZ. 


\section{$\begin{array}{llll}0.00 & 0.02 & 0.05 & \mathrm{UE}\end{array}$}
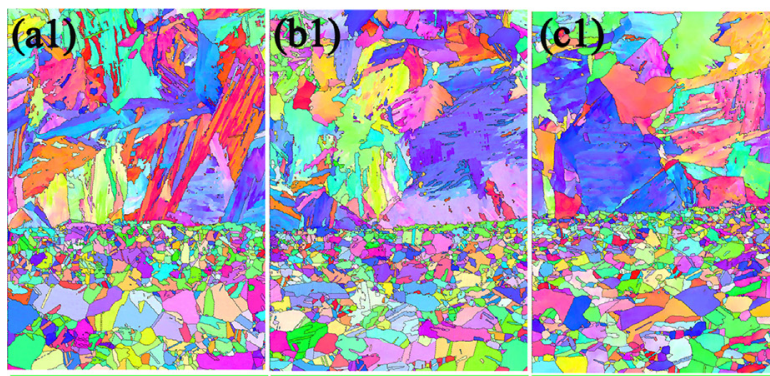

(d1)
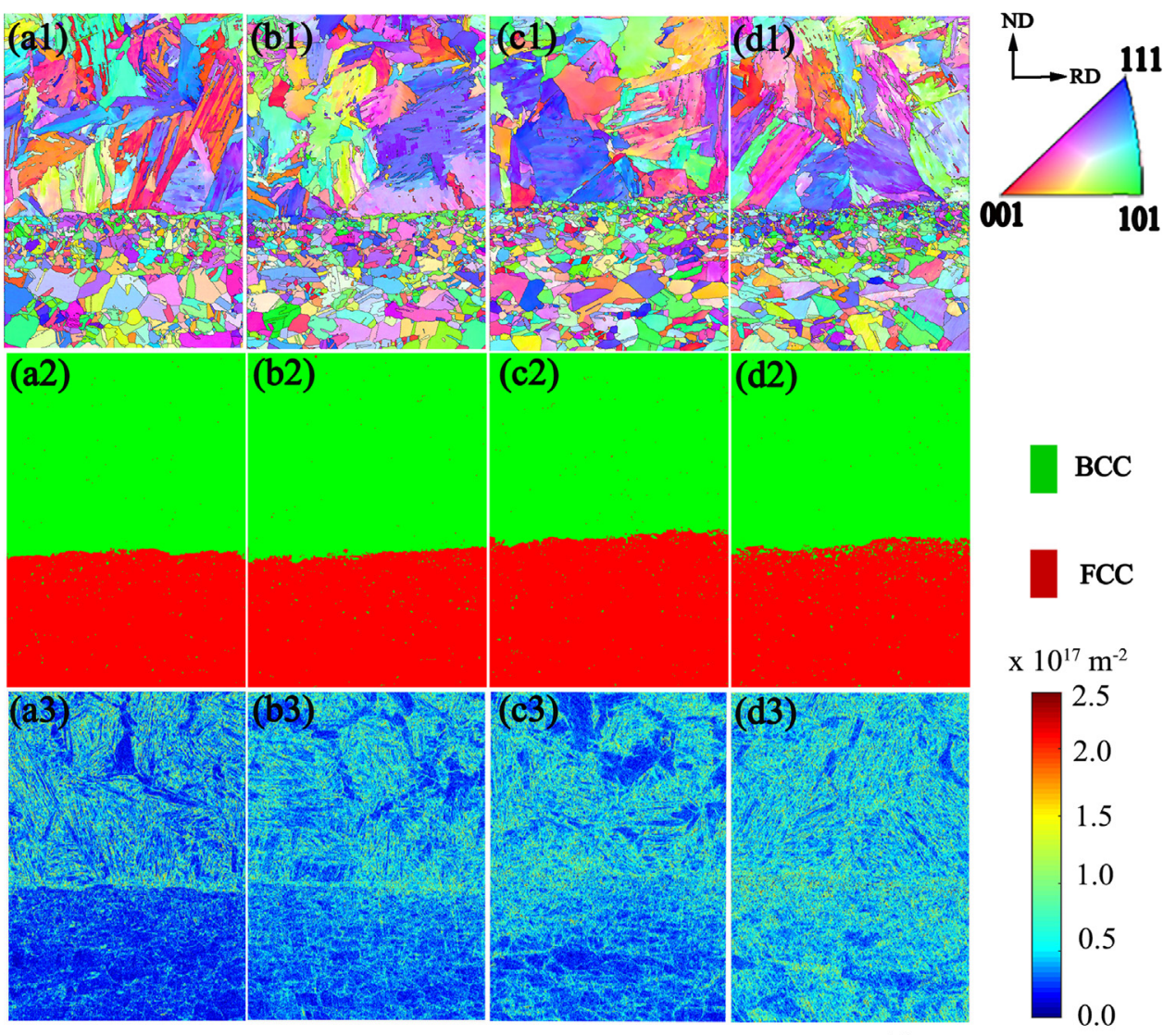

$15 \mu \mathrm{m}$

Fig. 6. Microstructure evolution across the interface at varying tensile strains ( $0 \%, 2 \%, 5 \%$, UE) during the tensile loading for the CR55\%+ WQ sample. (a1-d1) IPF images. (a2-d2) Phase distribution images. (a3-d3) Images of GND density mapping.

\section{(a)}

0

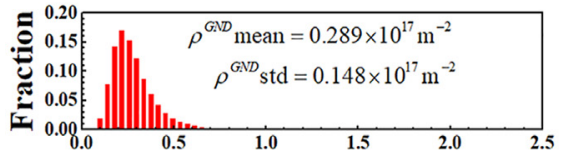

0.02

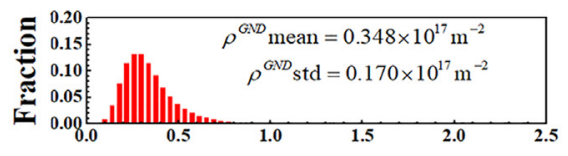

0.05

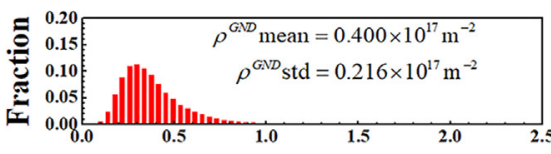

UE

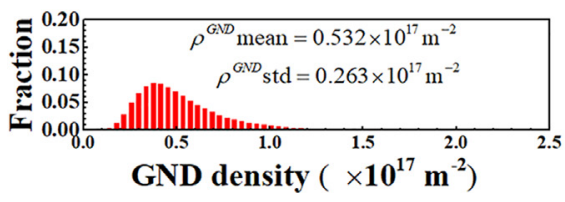

(b)
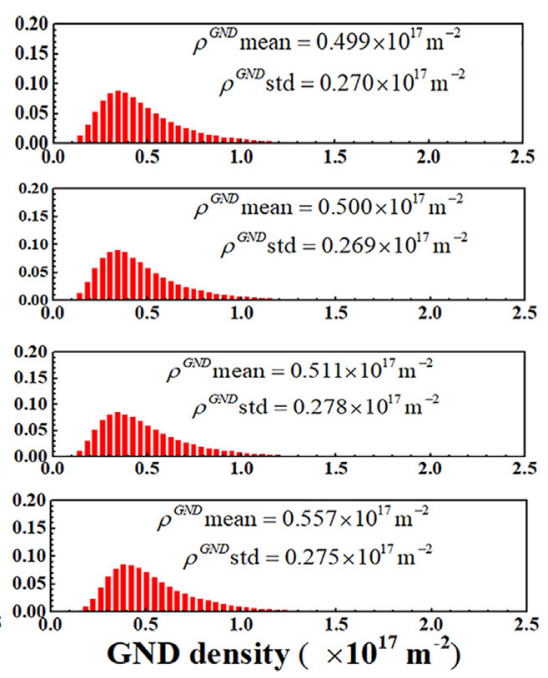

(c)
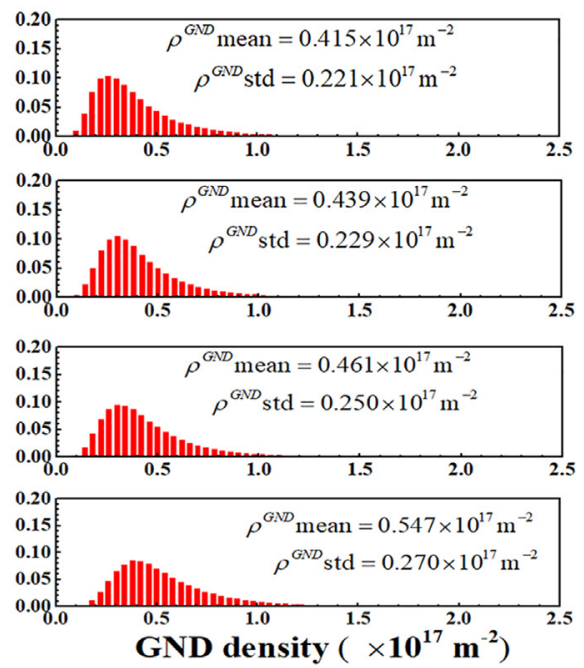

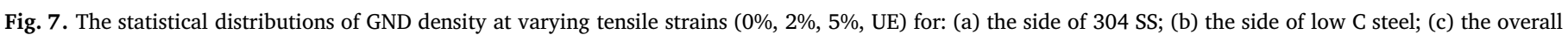
sample.

As indicated earlier, strain partitioning across the interfaces should occur during the plastic deformation for the current laminates, resulting in strong strain gradient at the area near the interfaces. Thus, how the GND density evolves with tensile strain should be characterized. In the present study, the local crystal orientations were measured for each EBSD image at the aforementioned tensile strains to investigate the evolution of GND density distribution at the area near the interfaces. From EBSD data, the local crystal orientations were determined using 
the kernel average misorientation (KAM) method [16]. Then the GND density information can be obtained using a simple method based on the strain gradient theory, which was proposed by Gao and Kubin $[34,36]: \rho_{G N D}=\frac{2 \theta}{l b}$. Where, $\rho_{G N D}$ is the GND density at local points, $\theta$ represents the misorientation at local points, $l$ is the unit length ( $100 \mathrm{~nm}$ in the present study) for the local points, and $b$ is the Burger's vector for the materials $(0.253 \mathrm{~nm}$ for $304 \mathrm{SS}, 0.248 \mathrm{~nm}$ for low $\mathrm{C}$ steel). Fig. 6a3-d3 show the evolution of GND density distribution mapping at the area near the interfaces for the CR55\% + annealing + WR sample $(0 \%, 2 \%, 5 \%, \mathrm{UE})$. It is clearly indicated that the overall average GND density increases with increasing applied tensile strain, which can be expected from the deformation physics of heterogeneous materials [16,26,37-42]. Fig. 7 displays the histogram distributions of GND density at varying applied tensile strains $(0 \%, 2 \%, 5 \%$, UE). The histogram distributions of GND density at the side of 304 SS are shown in Fig. 7a, the histogram distributions of GND density at the side of low C steel are displayed in Fig. 7b, and the histogram distributions of GND density for the whole map are plotted in Fig. 7c.

It should be noted that the GND density distribution is inhomogeneous in the whole map. One origin for the inhomogeneous distributions of the strain gradient and the GND density at the area near the interfaces could be from the grains with different grain sizes and different crystallographic orientations, in which GNDs can be generated at the randomly distributed GBs. However, the most contributions for the GNDs should be originated from the interfaces between the low $\mathrm{C}$ steel and the 304 SS, and these two sides show significant difference in mechanical properties. In order to minimize the effect from GBs and extract the effect of interfaces, the whole map was sliced into thin slabs parallel to the interfaces and the average GND density for each slab is plotted as a function of distance from the interface at varying applied tensile strains $(0 \%, 2 \%, 5 \%$, UE) in Fig. 8 a. These GND density distributions across the interface all show a peak at the interface, and gradually decreasing to a plateau for both sides. The plateau value for the side of low C steel is always higher than that for the side of 304 SS, while the difference between these two plateau values becomes smaller with increasing applied tensile strain. It is interesting to note that a relatively high GND density already exists in the area near the interfaces before the tensile loading ( $0 \%$ tensile strain). The initial high density GNDs in the area near the interfaces could be attributed to the two reasons: (i) The high internal residual stress induced by the different thermal expansions between the 304 SS and the low C steel during HR, annealing and WQ (The coefficients of thermal expansion are $17.8 \times 10^{-6} / \mathrm{K}$ and $14.5 \times 10^{-6} / \mathrm{K}$ for the $304 \mathrm{SS}$ and the low $\mathrm{C}$ steel, respectively, according to ASM Material Data Sheet); (ii) The high internal stress induced by the martensite transformation during WQ. These results also indicate that the strain gradient is inhomogeneous across the interface and becomes more and more severe during the tensile plastic deformation since the GND density can be related to the strain gradient $[34,36]$. Previous research $[15,16]$ have indicated that there might exist an optimum interface spacing, by which the density of GNDs can be maximized with high density of IZ and without overlapping of distribution of GNDs for each interface (i.e., the distribution of GNDs might be overlapped between the neighboring interfaces when the interface spacing is too small, which could be detrimental to the ductility). These designing principles need be further studied in the future.

Then the average GND densities for the side of 304 SS, the side of low $\mathrm{C}$ steel and the whole map are plotted as a function of applied tensile strain in Fig. 8b, and the corresponding increments of average GND densities during the tensile loading are shown Fig. 8c. As indicated in Fig. $8 b$ and c, the average GND densities for the side of 304 SS, the side of low $\mathrm{C}$ steel and the whole map all increase with increasing applied tensile strain. It is interesting to note that the GND density for the side of 304 SS increases from the very beginning of tensile loading, while the GND density for the side of low $\mathrm{C}$ steel keeps nearly a constant until $2 \%$ tensile strain and then increases with a lower speed. This behavior can be understood from the deformation physics of heterogeneous materials [38], i.e., the whole laminate deforms elastically with a very small strain, and then the softer 304 SS deforms plastically while the harder martensite phase in low $\mathrm{C}$ steel still deform elastically (a)

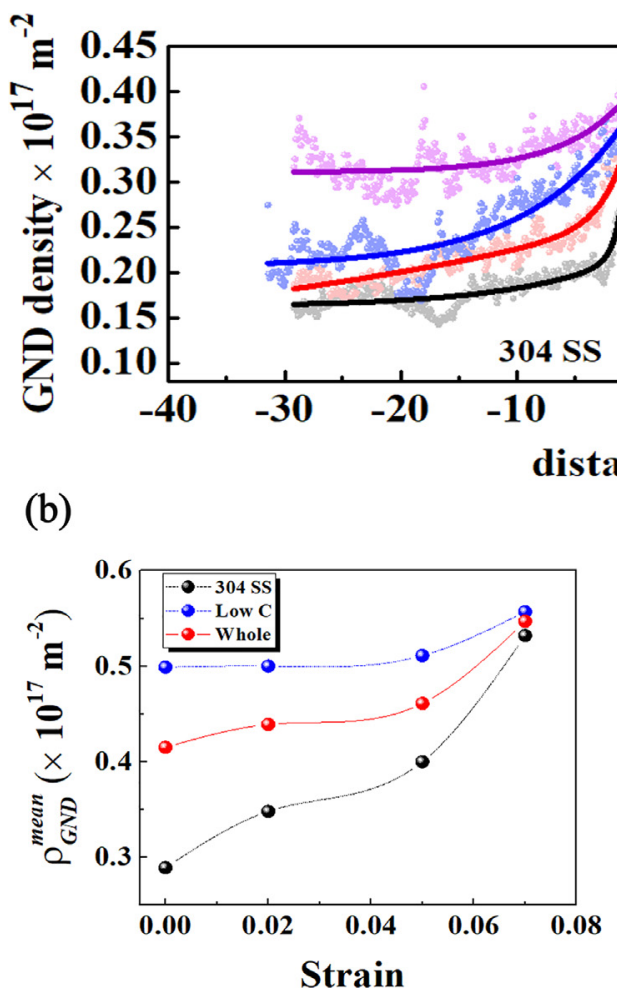

Fig. 8. (a) GND density distributions as a function of the distance from the interface at varying tensile strains $(0 \%, 2 \%, 5 \%$, UE) for the CR55\%+WQ sample. (b) Average GND densities for the side of 304 SS, the side of low $\mathrm{C}$ steel and the whole map as a function of applied tensile strain. (c) Increments of average GND density for the side of 304 SS, the side of low C steel and the whole map as a function of applied tensile strain. 
(a)

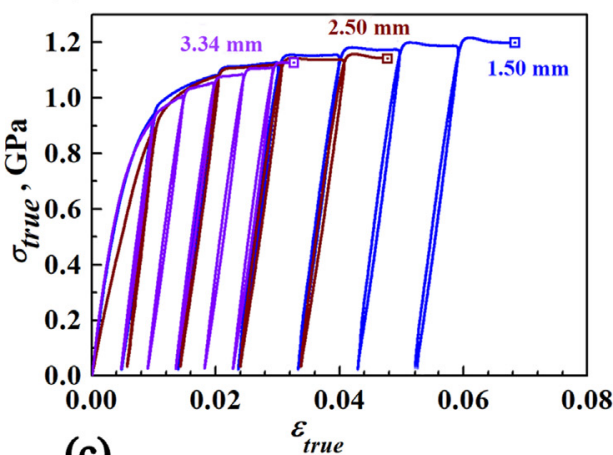

(c)

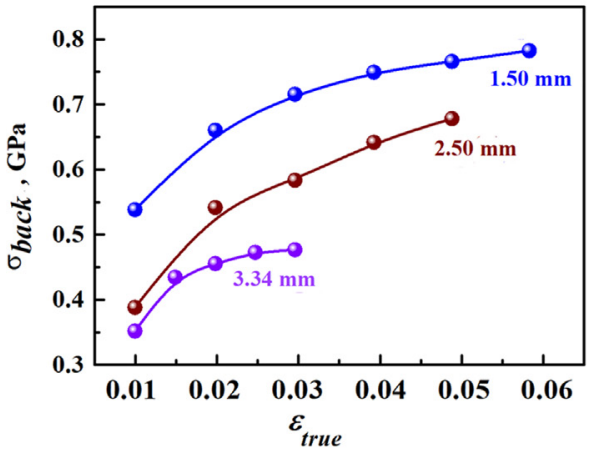

(b)

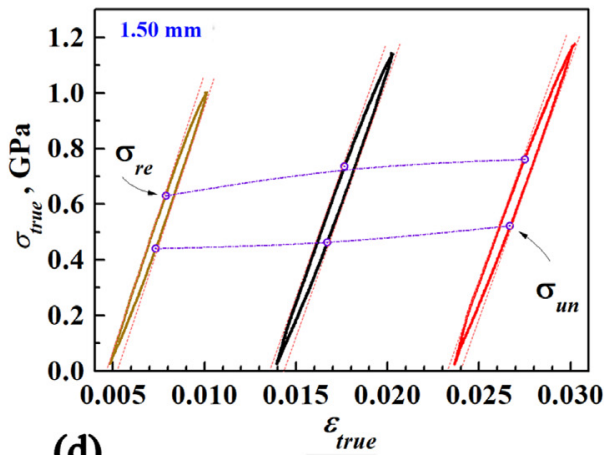

(d)

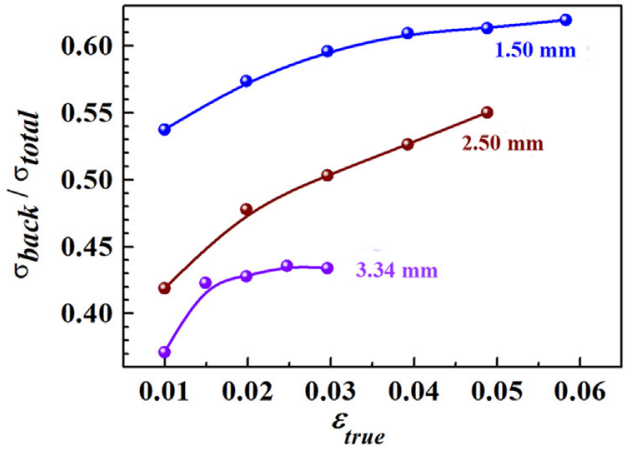

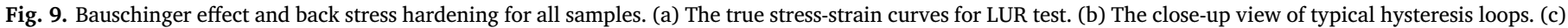
The evolutions of $\sigma_{\text {back }}$ with applied tensile strain for the CR +WQ samples. (d) The evolutions of $\sigma_{\text {back }} / \sigma_{\text {total }}$ with applied tensile strain for the CR + WQ samples.

at the elasto-plastic transition stage, and finally these two regions deform both plastically as a co-deformation stage. Thus, the elasto-plastic transition stage can be considered from the start of plastic deformation for 304 SS to about $2 \%$, the GND density increases for 304 SS due to plastic deformation while the GND density keeps nearly a constant for low $C$ steel due to the elastic deformation of martensite phase during this stage

\subsection{Effect of fraction of IZ on back stress hardening}

As indicated in previous papers [16,26,37-41], the good ductility and the high strain hardening in the heterogeneous structure can be attributed to the high back stresses that arise from plastic deformation incompatibility between different areas with different mechanical properties. The back stress hardening should also play an important role in the current laminates due to the different mechanical properties for the low C steel layer and the 304 SS layers. In this regard, the back stresses for all samples with various fractions of IZ have been measured using LUR tests. Fig. 9a shows the true stress-strain curves for LUR tests on all samples with various fractions of IZ, and Fig. 9b displays the close-up views of typical hysteresis loops at various pre-determined strains for the CR55\% + WQ sample. Then, the back stress can be estimated by the average value of the unloading yield stress and the reloading yield stress $\left(\sigma_{\text {back }}=\left(\sigma_{u}+\sigma_{r}\right) / 2\right)$, as proposed in our previous papers $[37,39]$. The effective stress for the forest dislocation hardening can be obtained from the total flow stress and the back stress as following: $\sigma_{\text {eff }}=\sigma_{\text {total }}-\sigma_{\text {back }}$. The evolutions of back stress as a function of applied tensile strain can be obtained from the hysteresis loops at various tensile strains, and are plotted in Fig. 9c. As indicated earlier, the initial residual stresses develop during HR, annealing and WQ, and these initial residual stresses should have influence on the nature of the elastoplastic transition and provide the initial back stress [43] (as indicated in Fig. 9c). However, the back stress hardening, i.e., the back stress increment with applied strain should be attributed to the plastic deformation incompatibility between the 304 SS and the low C steel during the subsequent tensile deformation. $\sigma_{b a c k} / \sigma_{\text {total }}$ can be considered as the contribution of back stress hardening to the overall strain hardening for the current laminates, thus the evolutions of $\sigma_{b a c k} / \sigma_{\text {total }}$ as a function of applied tensile strain are plotted in Fig. 9d for the CR +WQ samples with various fractions of IZ. It is interesting to note that high back stress hardening is observed for all samples since the magnitudes of $\sigma_{\text {back }} / \sigma_{\text {total }}$ all increase with increasing applied tensile strain. $\sigma_{\text {back }}$ and $\sigma_{\text {back }} / \sigma_{\text {total }}$ are observed to increase with a faster rate at the elasto-plastic transition stage $(<2 \%)$, and gradually slow down afterwards. This observation indicates that the back stress hardening should play a much more important role during the elasto-plastic transition stage, since the deformation incompatibility should be much larger at this stage. It also can be found that the contribution of back stress hardening in the overall strain hardening increases with increasing fraction of IZ. The back stress hardening is mainly originated from the distribution of GNDs at the interface area. Thus smaller interface spacing will result in higher fraction of IZ, thus higher density of GNDs in the whole sample. This higher density of GNDs will contribute higher back stress hardening for the samples with higher fraction of IZ (as observed in Fig. 9d), resulting in better tensile ductility (as indicated in Fig. 4).

\subsection{Fractography}

SEM was used to clarify the rupture mechanisms in the samples, especially at the area near the interface. Fig. 10a shows the fracture surface after the tensile deformation for the CR55\% + WQ sample, the corresponding close-up views for the area across the interface are given in Fig. 10b and d, and the corresponding close-up view for the area with a large distance from the interface at the side of low $\mathrm{C}$ steel is give in Fig. 10c. As indicated, the interface is still almost intact after fracture, it indicates that the HR bonding is strong enough to accommodate the tensile deformation without delamination, which is important to achieve good tensile ductility in current laminates. The side of 304 SS exhibits an obvious ductile fracture characteristic with a large number 

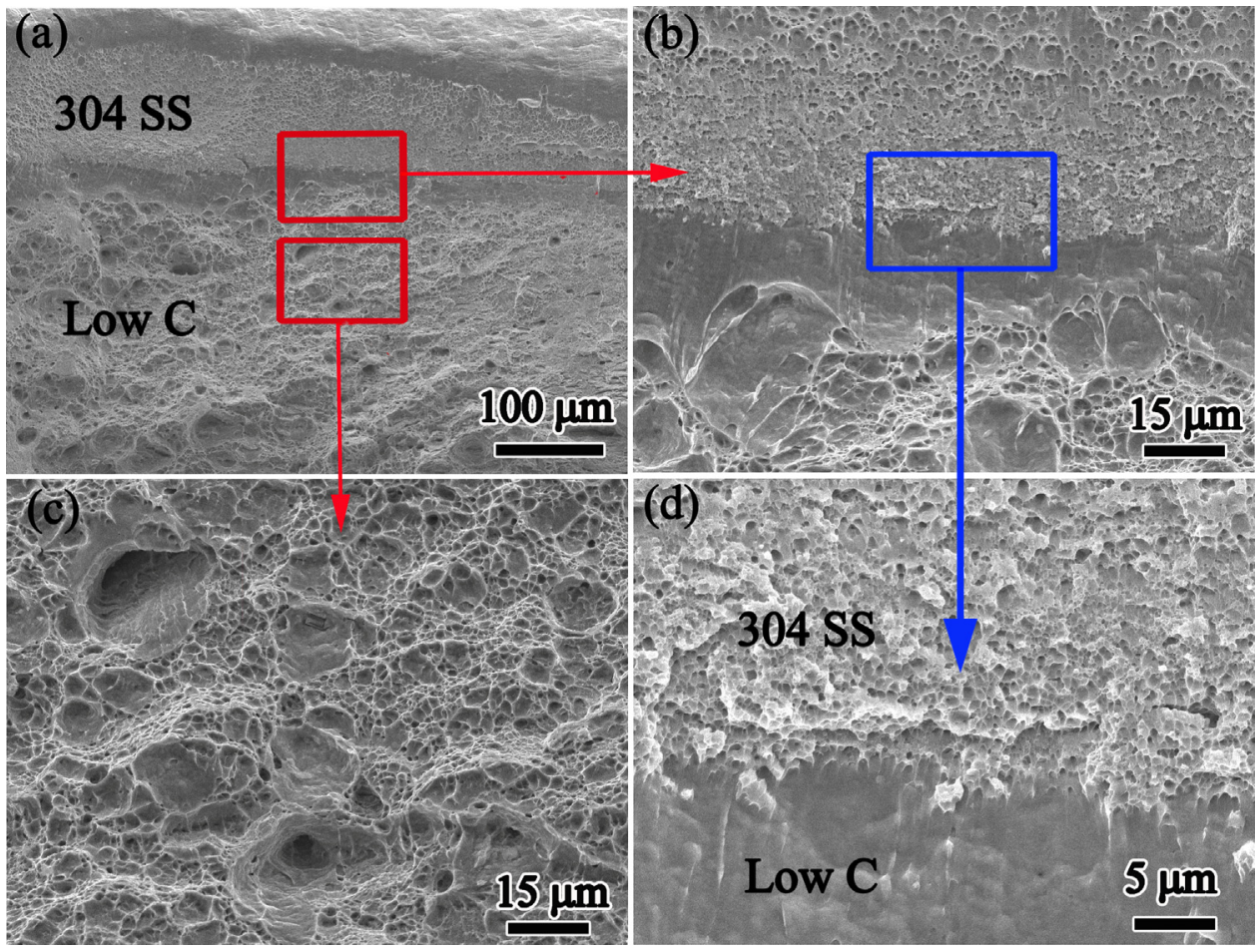

Fig. 10. (a) The fracture surface after the tensile deformation for the CR55\% + WQ sample. (b) The corresponding close-up view for the rectangular area across the interface marked in Fig. 10a. (c) The corresponding close-up view for the rectangular area with a large distance from the interface at the side of low $\mathrm{C}$ steel marked in a. (d) The corresponding close-up view for the rectangular area across the interface marked in $b$.

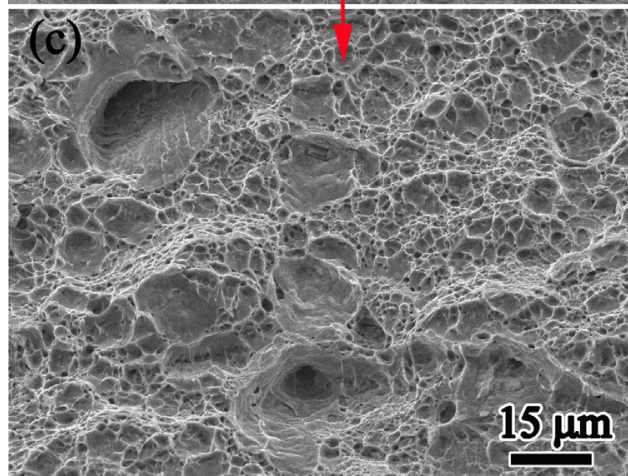

of dimples. It is also interesting to note that the size of dimples increases with increasing distance from the interface for the side of 304 SS, which could be due to the gradient grain size distribution for the side of 304 SS. At the side of low C steel, the fracture behavior is transited gradually from semi-cleavage fracture at the interface to ductile fracture with dimples at the large distance away from the interface. The size of dimples also increase with increasing distance from the interface for the side of low C steel. These observations indicate highly inhomogeneous plastic deformation and strain gradient across the interface for the laminates. As can be seen from the present results, the HR bonding and post processes can be considered as a powerful procedure to produce high-strength and good-ductility laminates, which have strong bonding interface and show no delamination after tensile deformation.

\section{Concluding remarks}

In the present study, the effect of fraction of IZ on the tensile deformation behaviors has been investigated in low C steel/304 SS laminates. The main findings can be summarized as follows:

(1) Similar distributions of chemical composition, grain size, phase and hardness across the interfaces were observed in the low C steel/304 SS laminates with varying fractions of IZ.

(2) With increasing fraction of IZ, the UTS and the UE were improved, while the YS was found to be a constant. The discontinuity of hardness across the interfaces is eliminated after tensile deformation, indicating strong strain partitioning and strain gradient at the area near the interfaces.

(3) The distributions of GND were observed to have a peak at the interface, high density of GNDs were found to accumulate in the IZ and increase with increasing applied tensile strain. Thus, these observations for improved tensile ductility with increasing fraction of IZ can be attributed to the role of IZ on the strain gradient and GNDs due to the deformation incompatibility across the interface, i.e. higher density of GNDs can be generated with increasing fraction of IZ, resulting in better UE.

(4) Stronger back stress hardening have been observed in the samples with higher fraction of IZ due to the higher density of GNDs accumulated in the samples, resulting in better mechanical properties. The present results provide insights and procedures to improve ductility without sacrifice of strength in the HR bonded laminates.

\section{Acknowledgements}

The work was supported by the National Key R\&D Program of China [Grant number 2017YFA0204402]; the National Natural Science Foundation of China [Grant numbers 11472286, 11672313, 11572328, 11790293], and the Strategic Priority Research Program of the Chinese Academy of Sciences [Grant number XDB22040503].

\section{References}

[1] R.Z. Valiev, I.V. Alexandrov, Y.T. Zhu, T.C. Lowe, Paradox of strength and ductility in metals processed by severe plastic deformation, J. Mater. Res. 17 (2002) 5-8.

[2] Y.T. Zhu, X.Z. Liao XZ, Nanostructured metals - retaining ductility, Nat. Mater. 3 (2004) 351-352.

[3] M.A. Meyers, A. Mishra, D.J. Benson, Mechanical properties of nanocrystalline materials, Prog. Mater. Sci. 51 (2006) 427-556.

[4] Y.M. Wang, E. Ma, Three strategies to achieve uniform tensile deformation in a nanostructured metal, Acta Mater. 52 (2004) 1699-1709.

[5] K. Youssef, M. Sakaliyska, H. Bahmanpour, R. Scattergood, C. Koch, Effect of stacking fault energy on mechanical behavior of bulk nanocrystalline $\mathrm{Cu}$ and $\mathrm{Cu}$ alloys, Acta Mater. 59 (2011) 5758-5764.

[6] L. Lu, Y.F. Shen, X.H. Chen, L.H. Qian, K. Lu, Ultrahigh strength and high electrical conductivity in copper, Science 304 (2004) 422-426.

[7] X.L. Wu, Y.T. Zhu, Heterogeneous materials: a new class of materials with unprecedented mechanical properties, Mater. Res. Lett. 5 (2017) 527-532.

[8] E. Ma, T. Zhu, Towards strength-ductility synergy through the design of heterogeneous nanostructures in metals, Mater. Today 20 (2017) 323-331.

[9] L. Lu, X. Chen, X. Huang, K. Lu, Revealing the maximum strength in nanotwinned copper, Science 323 (2009) 607-610.

[10] X.Y. Li, Y.J. Wei, L. Lu, K. Lu, H.J. Gao, Dislocation nucleation governed softening and maximum strength in nano-twinned metals, Nature 464 (2010) 877-880.

[11] X.L. Wu, F.P. Yuan, M.X. Yang, P. Jiang, C.X. Zhang, L. Chen, Y.G. Wei, E. Ma, Nanodomained nickel unite nanocrystal strength with coarse-grain ductility, Sci. Rep. 5 (2015) 11728.

[12] F.P. Yuan, X.L. Wu, Size effect and boundary type on the strengthening of nanoscale domains in pure nickel, Mater. Sci. Eng. A 648 (2015) 243-251.

[13] P.V. Liddicoat, X.Z. Liao, Y.H. Zhao, Y.T. Zhu, M.Y. Murashkin, E.J. Lavernia, R.Z. Valiev, S.P. Ringer, Nanostructural hierarchy increases the strength of aluminum alloys, Nat. Commun. 1 (2010) 63.

[14] G. Liu, G.J. Zhang, F. Jiang, X.D. Ding, Y.J. Sun, J. Sun, E. Ma, Nanostructured high- 
strength molybdenum alloys with unprecedented tensile ductility, Nat. Mater. 12 (2013) 344-350.

[15] X.L. Ma, C.X. Huang, W.Z. Xu, H. Zhou, X.L. Wu, Y.T. Zhu, Strain hardening and ductility in a coarse-grain/nanostructure laminate material, Scr. Mater. 103 (2015) $57-60$.

[16] X.L. Ma, C.X. Huang, J. Moering, M. Ruppert, H.W. Höppel, M. Göken, J. Narayan, Y.T. Zhu, Mechanical properties of copper/bronze laminates: role of interfaces, Acta Mater. 116 (2016) 43-52.

[17] H. Wu, G.H. Fan, M. Huang, L. Geng, X.P. Cui, H.L. Xie, Deformation behavior of brittle/ductile multilayered composites under interface constraint effect, Inter, J. Plast. 89 (2017) 96-109.

[18] M. Ojima, J. Inoue, S. Nambu, P. Xu, K. Akita, H. Suzuki, T. Koseki, Stress partitioning behavior of multilayered steels during tensile deformation measured by in situ neutron diffraction, Scr. Mater. 66 (2012) 139-142.

[19] H.S. Liu, B. Zhang, G.P. Zhang, Delaying premature local necking of high-strength Cu: a potential way to enhance plasticity, Scr. Mater. 64 (2011) 13-16.

[20] H. Wu, B.C. Jin, L. Geng, G.H. Fan, X.P. Cui, M. Huang, R.M. Hicks, S. Nutt, Ductilephase toughening in TiBw/Ti-Ti3Al metallic-intermetallic laminate composites, Metall. Mater. Trans. A 46A (2015) 3803-3807.

[21] S. Zheng, I.J. Beyerlein, J.S. Carpenter, K. Kang, J. Wang, W. Han, N.A. Mara, highstrength and thermally stable bulk nanolayered composites due to twin induced interfaces, Nat. Commun. 4 (2013) 1696.

[22] I.J. Beyerlein, J.R. Mayeur, S. Zheng, N.A. Mara, J. Wang, A. Misra, Emergence of stable interfaces under extreme plastic deformation, Proc. Natl. Acad. Sci. 111 (2014) 4386-4390.

[23] M.F. Ashby, The deformation of plastically non-homogeneous materials, Philos. Mag. 21 (1970) 399-424.

[24] A. Misra, J.P. Hirth, R.G. Hoagland, Length-scale-dependent deformation mechanisms in incoherent metallic multilayered composites, Acta Mater. 53 (2005) 4817-4824.

[25] Y.M. Wang, M.W. Chen, F.H. Zhou, E. Ma, High tensile ductility in a nanostructured metal, Nature 419 (2002) 912-915.

[26] X.L. Wu, M.X. Yang, F.P. Yuan, G.L. Wu, Y.J. Wei, X.X. Huang, Y.T. Zhu, Heterogeneous lamella structure unites ultrafine grain strength with coarse-grain ductility, Proc. Natl. Acad. Sci. USA 112 (2015) 14501-14505.

[27] R. Yuan, I.J. Beyerlein, C.Z. Zhou, Homogenization of plastic deformation in heterogeneous lamella structures, Mater. Res. Let. 5 (2017) 251-257.

[28] X.L. Wu, P. Jiang, L. Chen, Y.T. Zhu, Synergetic strengthening by gradient structure, Mater. Res. Lett. 2 (2014) 185-191.
[29] X.L. Wu, P. Jiang, L. Chen, F.P. Yuan, Y.T. Zhu, Extraordinary strain hardening by gradient structure, Proc. Natl. Acad. Sci. USA 111 (2014) 7197-7201.

[30] T.H. Fang, W.L. Li, N.R. Tao, K. Lu, Revealing extraordinary intrinsic tensile plasticity in gradient nano-grained copper, Science 331 (2011) 1587-1590.

[31] Y.J. Wei, Y. Li, L. Zhu, Y. Liu, X. Lei, G. Wang, Y. Wu, Z. Mi, J. Liu, H. Wang, H.J. Gao, Evading the strength- ductility trade-off dilemma in steel through gradient hierarchical nanotwins, Nat. Commun. 5 (2014) 3580.

[32] X.L. Wu, M.X. Yang, F.P. Yuan, L. Chen, Y.T. Zhu, Combining gradient structure and TRIP effect to produce austenite stainless steel with high strength and ductility, Acta Mater. 112 (2016) 337-346.

[33] N.A. Fleck, G.M. Muller, M.F. Ashby, J.W. Hutchinson, Strain gradient plasticity: theory and experiment, Acta Metal. Mater. 42 (1994) 475-487.

[34] H. Gao, Y. Huang, W.D. Nix, J.W. Hutchinson, Mechanism-based strain gradient plasticity - I. Theory, J. Mech. Phys. Solids 47 (1999) 1239-1263.

[35] J. Talonen, H. Hänninen, Formation of shear bands and strain-induced martensite during plastic deformation of metastable austenitic stainless steels, Acta Mater. 55 (2007) 6108-6118.

[36] L.P. Kubin, A. Mortensen, Geometrically necessary dislocations and strain gradient plasticity: a few critical issues, Scr. Mater. 48 (2003) 119-125.

[37] M.X. Yang, Y. Pan, F.P. Yuan, Y.T. Zhu, X.L. Wu, Back stress strengthening and strain hardening in gradient structure, Mater. Res. Lett. 4 (2016) 145-151.

[38] M.X. Yang, F.P. Yuan, Q.G. Xie, Y.D. Wang, E. Ma, X.L. Wu, Strain hardening in Fe16Mn-10Al-0.86C-5Ni high specific strength steel, Acta Mater. 109 (2016) $213-222$.

[39] Y. Ma, M.X. Yang, P. Jiang, F.P. Yuan, X.L. Wu, Plastic deformation mechanisms in a severely deformed Fe-Ni-Al-C alloy with superior tensile properties, Sci. Rep. 7 (2017) 15619.

[40] J.X. Xing, F.P. Yuan, X.L. Wu, Enhanced quasi-static and dynamic shear properties by heterogeneous gradient and lamella structures in 301 stainless steels, Mater. Sci. Eng. A 680 (2017) 305-316.

[41] L. Chen, F.P. Yuan, P. Jiang, J.J. Xie, X.L. Wu, Mechanical properties and deformation mechanism of Mg-Al-Zn alloy with gradient microstructure in grain size and orientation, Mater. Sci. Eng. A 694 (2017) 98-109.

[42] F.P. Yuan, P. Chen, Y.P. Feng, P. Jiang, X.L. Wu, Strain hardening behaviors and strain rate sensitivity of gradient-grained Fe under compression over a wide range of strain rates, Mech. Mater. 95 (2016) 71-82.

[43] K. Spencer, K.T. Conlon, Y. Bréchet, J.D. Embury, The strain induced martensite transformation in austenitic stainless steels, Part 2 - Effect of internal stresses on the mechanical response, Mater. Sci. Tech. 25 (2009) 18-28. 